\title{
The Research on the Influences of Bilateral Diplomatic Relations to the Foreign Student Scale
}

\author{
Tang Jing and Wang Xiting
}

\begin{abstract}
Bilateral diplomatic relations is an essential approach to play political influences of our country, thereby attracting foreign students to study in China. This research which analyzes 36 related countries of the Belt and Road policy, based on panel date of 2003-2014, found that the orientation of political relations, the time of diplomatic relations establishment, and friendly impression of a city all have significantly positive impact on foreign students. The alienation of culture has a significantly negative impact on foreign students. Bilateral diplomatic relations can efficiently improve obstacle effect brought by the alienation of culture and enhance the amount of foreign students. In order to improve the educational development of overseas students and build the brand of "study in China", it is necessary to attach importance to the leading role of formal political diplomacy as well as the important role of non-governmental diplomacy.
\end{abstract}

Index Terms-Political Relations; the Time of Diplomatic Relations Establishment; High-level Visits; Friendship Cities; Cultural Distance

\section{INTRODUCTION}

Enhancing the amount of foreign students studying in China is an essential way to realize mutual learning between different civilizations at home and abroad, and it is also an important embodiment of China's growing openness and inclusiveness. It is not only an important carrier for deepening the cultural exchanges between China and foreign countries and enhancing the country's soft power, but also a crucial way to provide international talent support for major national strategies. Since China is a large country of education, expanding the scale of international students and improving the personnel training quality in China not only become an important part to build the Belt and Road and link people of all countries along it, but also help cultivate a large amount of professionals for the Belt and Road Initiative, providing talent support for countries along the route to benefit connectivity of policy, infrastructure, trade, finance and people.

In order to give full play to the important role of studying in China in politics, economy, society, culture and other fields, China began to implement "the Program of Studying Abroad in China" in 2010. Then in 2014, China held a national conference on studying abroad, planning to develop the issue of studying in China for the first time. In 2016, "Several Opinions on How to Do a Good Job in Education Opening to the Outside World in the New Period" and "Promoting the Co-construction of the Belt and Road Education Action" were implemented one after

Tang Jing is with the School of Economics and Trade, Guangdong University of Foreign Studies, China (e-mail: 15454295@qq.com)

Wang Xiting is with the School of Economics and Trade, Guangdong University of Foreign Studies, China (e-mail: starstudded28@yahoo.com) another by the Chinese government, which further promoted the development of the issue of studying abroad in China. The introduction of a series of policies on studying in China has effectively enhanced the attraction of studying in China, and gradually created the brand of "studying in China". The range of countries of origin of students studying in China has continuously increased, and the scale of international students in China has achieved sustained growth. According to the statistics from the Ministry of Education in China, in 2009, the number of students studying in China was 44700, while in 2016 there were 442800 students from 205 countries and regions, an increase of nearly tenfold, and a large number of international talents who built up strong relationship with China were trained. And China has become Asia's largest destination for studying abroad.

Although the concept of "Studying in China and Studying Abroad" has been vigorously promoted in recent years, as a developing country, China is still facing the problem that the attractiveness of studying abroad in China is not high enough, and the "studying abroad deficit" is still grim. The problems of unbalanced development and unreasonable structure are still outstanding. In different levels of education, the proportion of international students to the total number of students in this category is still at a relatively low level, which is far less than that of the powerful countries in Europe and the United States. From the perspective of international comparison, there is great room for China to attract international students in the future, but it still facing many challenges of expanding the scale of international students.

Many literatures have discussed the influencing factors and development countermeasures of studying in China (Liu Yang, Wang Hui, Kong prosperous, 2013; Song Huasheng, Liu Li, 2014; Lu Na, 2015; (Lin Hang, Xie Zhizhong, Zheng Ruiyun, 2016), but most of them did not notice the diplomatic attributes of studying in China and the important potential impact of bilateral diplomatic relations. The basic starting point for studying abroad is to open up service education to the outside world, train international talents who may build up strong relationship with China and focus on national strategy. Both in theory and in practice, bilateral diplomatic relations are important factors affecting students studying in China. Based on this, this paper attempts to quantitatively investigate the influence of bilateral diplomatic relations on studying in China from multiple aspects, such as the positioning of bilateral diplomatic relations, the history of diplomatic relations, bilateral high-level visits and friendly cities. At the same time, considering the hindrance and influence of cultural differences in studying in China, this paper will further investigate the interaction between bilateral diplomatic relations and cultural distance. 


\section{REVIEW OF POLICY SUCCESSION AND LITERATURE}

After the initial period (1950-1965), the period of stagnation and rectification (1966-1977), the period of reform and opening-up (1978-1989) and the period of rapid development (1992-present), the education for international students in China has taken shape. Since the 16th National Congress, the Party and the country have attached great importance to the issue of studying in China.

In 2013, General Secretary Xi Jinping clearly put forward the general policy of "supporting students studying abroad, encouraging them to return to China, coming and going freely and playing their roles" in the European and American students association. In 2014, the Ministry of Education made a systematic plan to study in China for the first time in the national conference on studying abroad. In 2016, the national conference on management of studying abroad in China was held in Beijing. Xi Jinping stressed that studying abroad should be adapted to the overall situation of national development and the overall situation of the Party and state work, and strive to create a new phase in studying abroad. Two important documents, "Several Opinions on How to Do a Good Job in Education Opening to the Outside World in the New Period" and "Promoting the Co-construction of the Belt and Road Education Action" have also made major strategic plans for promoting the internationalization of education around the internationalization of education.

With the help of policies, the cause of studying abroad in China has flourished. Throughout 2016, more than 800 colleges and universities, scientific research institutes and other teaching institutions in 31 provinces (autonomous regions, and municipalities directly under the Central Government) in the country attracted 442800 international students studying in China, 45,100 more than in 2015, and an increase of $11.35 \%$ (the above data do not include Hong Kong, Macao and Taiwan). Countries along the Belt and Road have emerged as a new force. In addition to Thailand, the number of students from Indonesia, India, Pakistan and other countries are also among the top 10 countries of origin for international students. The number of Pakistani students in China was 13,360 in 2014 , ranking eighth among the countries of origin for international students, and rose to fourth in 2016. In 2014, the number of Kazakh students studying in China was 11,764 , which increased by 15.1 times compared with 2005, with the largest increase.

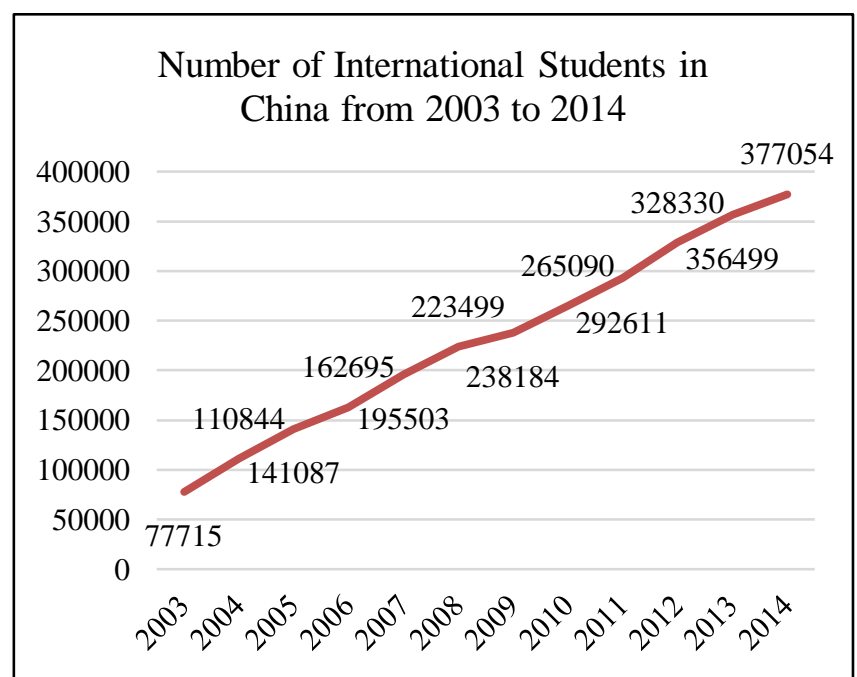

The changes in diplomatic relations and the political situation in China have created a stable and harmonious environment and provided institutional guarantees for foreign students to come to China. As the "Davos" speech shows its courage to take responsibility, China plays an increasingly important role in the international political stage and uses international influence to conduct diplomacy. Political factors, especially bilateral relations, play a crucial part in it (Xu Chen-sheng, et al., 2016; Lien Tai-hsiang, 2014). In all kinds of documents, scholars found that foreign students from developed countries paid more attention to the political stability of China (Song Huasheng, Liu Li, 2014) and Yang Yunsheng (2015) mentioned that colleges and universities should seize the favorable conditions of foreign policies of China to develop the issue of studying in China. Lin Hang et al. (2016) further found that compared with the developed countries, the newly built Confucius Institute is more conducive to attracting overseas students in the developing countries. There are also many scholars notice that friendly bilateral relations contribute to the deepening of economic, trade, cultural and other aspects of the two sides. Based on the bilateral relations between China and the United States, China and South Korea and China and Kazakhstan, some scholars deeply analyze the influence of bilateral relations between different countries on overseas students coming to China. All of these reflect that the political and diplomatic relations have a strong influence on the scale of foreign students coming to China.

However, on the other hand, there are still many challenges to better promote the brand of studying in China and expand the number of foreign students in China. In particular, there is a lack of literature to examine the influence of political and diplomatic relations on the scale of foreign students in China. Therefore, the perspective of bilateral diplomatic factors provides a unique perspective for the scale study of foreign students in China. Firstly, from the angle of institutional theory, the influence of political relationship orientation, the historical time of the establishment of diplomatic ties, bilateral high-level visits and non-governmental diplomatic friendship cities on the scale of foreign students in China is considered. The heterogeneity of political diplomacy is considered, which is more systematic and explanatory. Secondly, the existing literature mostly considers the influence of changes in foreign policy on studying abroad in China from a static point of view, neglecting the connotation of "initiative" in diplomacy, and the exchange of visits by bilateral high-level officials can better reflect the subjective initiative of both sides in order to promote studying abroad in China, which has more practical significance. Thirdly, this paper further considers the interaction between political diplomacy and cultural factors, and deeply analyzes the extent to which political diplomacy factors affect the scale of studying in China. Last but not least, the selection sample is extensive, taking into account the geographical distance, cultural distance, local economic level, as well as demographic factors.

\section{INFLUENCE MECHANISM AND RESEARCH HYPOTHESIS}

The bilateral political and diplomatic relations provide an opportunity for the trade of education services, and also provide a platform for the exchange of information on related study policies of China. From the point of view of the development quantity of overseas students in China, the degree of friendship and diplomatic relations between 
countries have a significant impact on the scale of foreign students and the distribution of the source of foreign students in China. But what are the important factors involved in bilateral political diplomacy? Does each factor contribute to the growth of international students in China? What is its contribution to the education service trade of China? Will cultural barriers be effectively removed? To answer these questions, we need rigorous theoretical deduction and empirical test.

Studying in China has inherent diplomatic attributes in the stage of the People's Republic of China. In essence, political bilateral diplomatic relations are a specific institutional arrangement with subjective initiative between two countries. In order to maintain national security, strengthen economic exchanges, expand international influence and other strategic considerations, one country will form different political and diplomatic relations with other countries, which represents the complex relations between two nations. Bilateral political diplomacy is conducive to mutual understanding, mutual trust and mutual exchanges between the two sides, thus reducing uncertainties caused by bilateral political conflicts and bias. Positive bilateral political interaction help enhance the educational influence and soft power of China in the countries of origin, so as to change the discriminatory or resistant preference of higher education in the countries of origin. The Chinese government can also exert certain political pressure on the countries of origin through positive bilateral diplomatic relations, so as to prevent the governments of the countries of origin from formulating corresponding discriminatory provisions or policies against China's overseas study and hindering the development of education for overseas study in China.

To be specific, political and diplomatic relations include long-term and short-term, formal and informal parts. Formal political and diplomatic relations mainly include the positioning of long-term political relations and the history of the establishment of diplomatic relations and short-term bilateral high-level visits, etc. The informal relationship mainly includes the trust between leaders and the friendship between the two countries, such as the construction of friendship cities between the two sides. Compared with the long-term orientation of formal diplomatic relations, shortterm bilateral high-level meetings and informal friendship city exchanges have attracted the attention of scholars (Yang Lianxing, 2016). Therefore, when studying the mechanism of the influence of bilateral diplomatic relations on the host country's students studying in China, this paper specifically distinguishes the different roles of four tools, including the positioning of bilateral political relations, the history of diplomatic relations, bilateral high-level visits and non-governmental diplomatic methods.

\section{A. The Orientation of Bilateral Political Relations Provides a Formal Institutional Guarantee for Foreign Students in China}

For foreign students in China, the nature of long-term political relations, especially the long-term formal institutional arrangements provided by bilateral political relations, and the function of the system is to create order and promote smooth transactions in economic activities. The positioning of bilateral political relations is conducive to the creation and improvement of the policy rules for studying abroad in the two countries and the promotion of in-depth educational cooperation between the two sides. The uncertain institutional environment of the host country will significantly inhibit the willingness to study in China, especially the mutual recognition of academic qualifications, enrollment Numbers and immigration policies that have a significant impact on international students are reflected in the political relations between the two countries. If the interests of the two countries are not consistent, some political conflicts, such as border conflicts and human rights issues, will seriously affect the scale of enrollment of local students. Therefore, changes in the positioning of bilateral diplomatic relations will directly affect the scale of source countries.

The scale of foreign students in China depends on the top-level design and mechanism construction of China's global partnership network. Only by developing highquality diplomatic relations and building a network of partnerships of strategic mutual trust can China better meet its needs in various fields. Among them, according to diplomatic terms, "strategic cooperative partnership", "strategic cooperative partnership", "comprehensive friendly cooperative partnership", "comprehensive cooperative partnership", "friendly cooperative partnership or good-neighborly cooperative partnership of mutual trust" represent different degrees of diplomacy. Correspondingly, there are countries with normal diplomatic relations and those without. Therefore, this paper assigns the political and diplomatic inertia between the two countries according to the closeness of diplomatic relations.

In addition, since the founding of the People's Republic of China, the central tendency of the establishment of diplomatic relations between China and other countries is of great significance to the study on the scale of foreign students in China. From the perspective of China's foreign policy strategy, through the "peaceful foreign policy" (1949-1972), "one line, one large area" (1972-1979), as well as the early 1980 s to the present, China's foreign relations have taken on new forms, and remarkable progress has been made in its relations with neighboring countries and countries around the world. We believe that if the two sides establish diplomatic ties with a longer history, China's influence in the region will be greater, and its economic and trade exchanges in various fields will be more sufficient, which will be more conducive to strengthening the willingness of students of that region to study in China. Thus, the impact of the establishment of diplomatic relations on the scale of foreign students in China can not be ignored.

Therefore, the first hypothesis in the following is proposed:

1A: The degree of positioning of bilateral political relations positively influences the number of foreign students from host countries.

1B: The time of establishment of diplomatic relations between the two sides has a positive impact on the number of foreign students in China.

\section{B. High-level Visits Have Sent an Effective Signal to the Countries of Origin of Overseas Students}

High-level exchange of visits is conducive to transmitting the political preference signals between China and the countries of origin and enhancing the enthusiasm and 
confidence of students from the countries of origin. In light of political science, public interest is the collection of private interests. High-level visits between countries can reduce transaction costs for the internationalization of education through friendly consultation, promote the growth of the scale of international students in China and significantly increase the number of international students in China. At the same time, the continuous practice of exchanges between the leaders of the two countries can enhance the understanding of the political system, economic strength and cultural factors of the two sides and help to achieve a degree of "empathy". This kind of good communication and cooperation experience can create a friendly atmosphere, promote the in-depth economic, political and cultural cooperation between the two sides, form some appropriate norms accepted by both sides, and promote the mutual recognition of academic qualifications and the agreement on the terms of study abroad.

The process of the high-level meeting between the two sides is also a socialization process. The positive interaction between the senior leaders can make the image of China deeply rooted in the hearts of the local people, promote the local people to know more about Chinese culture, send a friendly signal and increase the willingness of local students to come to China. At the same time, this paper believes that the President or premier of the state council to participate in the visit or visit, really represents the country and the government. Referring to the practice of Nitsch and Zurich (2008), in this study, we believe that if Chinese President or premier of the state council meets with leaders of countries along the Belt and Road, or they hold meetings in third countries, it can be called bilateral high-level visits. According to statistics, we have got the basic variable VISIT.

The second hypothesis in the following is proposed:

Bilateral high-level visits help increase the number of foreign students in host countries.

\section{Non-governmental Friendship Cities Provide Information Dissemination for Foreign Students in China}

Friendship cities are informal institutional arrangements in bilateral political relations. After Friedman (1986) proposed the "world cities hypothesis", the importance of cities as economic units in the global governance system rose rapidly. International friendship city, a non-state actor, has become an important role in international politics (Zhao Hanqing, 2012). As an extension of national diplomacy in local regions, friendship city is usually regarded as an official relationship of folk diplomacy.

The establishment of friendship cities represents the friendly exchanges between the two countries and is a way for the people to carry out substantive exchanges and cooperation. Through the construction of friendship cities, the two sides can enhance the collision of cultures and ideologies and better understand bilateral relations and friendly exchanges. As China has taken an active part in global governance, its cooperation with overseas local governments has become more extensive. International cooperation between local governments has also gone deep into almost all local affairs, providing good conditions for the two sides to expand their acceptance of common development. In addition to sending overseas students and scientific researchers to study in the local areas, the cultural integration activities aimed at teenagers carried out by friendship cities have deepened the understanding of each other's urban culture, promoted the local yearning for Chinese culture and opened up a new market for overseas study. Meanwhile, friendship cities can better publicize China's culture and soft power. By publicizing the great achievements of China's economic and social development, natural landscape, customs and so on, it can form a pulling force for overseas students who want to travel to China (Brodin, 2010).

Therefore, the third hypothesis is proposed:

The construction of sister cities will positively promote the number of foreign students in China.

\section{MODEL CONSTRUCTION}

\section{A. Samples}

The Belt and Road is an international regional economic cooperation initiative, and there is no accurate spatial scope definition at present. Based on the practice of Chen Wanling (2015), this paper limits the countries and regions along the Belt and Road to 64 countries, and refers to the ranking of the number of foreign students in China and the availability of the data, as well as the number of relations with China's overseas students and bilateral political relations. Finally, this paper chooses 36 countries and regions of the five continents including Russia, South Korea, Japan, Singapore, France, Germany, Tanzania, Yemen, Nepal, Columbia, Australia, Myanmar, Pakistan, Spain, the Philippines, Malaysia, Thailand, Italy, India, Vietnam, Canada, the United States, Guinea, Ghana, Great Britain, Nigeria, Mexico, Turkey, the Democratic Republic of the Congo, Ukraine, Indonesia, Bangladesh, Uzbekistan and Kyrgyzstan, Kazakhstan and Laos, basically covers the number of the students of the top 20 countries. Due to the availability of data, the study period is set from 2003 to 2014, and 434 sample observations are finally obtained in this paper.

\section{B. Variables and Measurements \\ a. Number of Foreign Students in China (Stu)}

The data of foreign students in China mainly come from the brief statistics of national foreign students in China from 2004 to 2014. Due to the unpublished report of 2015 and the absence of data on some countries of origin, the rest of the data are obtained from the Ministry of Education website and source country website. The number of foreign students in China was taken as the explained variable.

\section{b. Positioning of Bilateral Political Relations (degree)}

The positioning of bilateral political relations is the core explanatory variable of this paper. Referring to the positioning of political relations in existing literature, the valuation method of He Shufeng (2009) and the official positioning of political relations between China and the host country, this paper assigns 5 points to the strategic partner, 4.5 to the strategic partner and 3.5 to the comprehensive friendly partner. Comprehensive cooperative partner is assigned a value of 3 , friendly cooperative partner or goodneighborly cooperative partnership of mutual trust is assigned a value of 2 , countries with normal diplomatic 
relations are assigned a value of 1 , and countries without diplomatic relations are assigned a value of 0 .

\section{c. Time of Establishing Diplomatic Relations (dtime)}

The time of establishing diplomatic relations represents the duration of diplomatic relations between China and the host country (in years). In this paper, the difference between the years of investigation and the years of diplomatic relations between the two sides is measured, and the specific data are collected manually from the website of the Ministry of Foreign Affairs.

\section{d. High-level Visits (visit)}

High-level visits indicate the number of visits by political leaders of the two countries in a given year. Referring to $\mathrm{Xu}$ Chensheng's (2015) approach, political diplomacy between senior leaders includes visiting and going abroad. The specific information comes from "diplomatic developments" on the website of the Ministry of Foreign Affairs.

\section{e. $\quad$ Friendship Cities (fcity)}

Friendship cities indicate the status of establishing friendship cities between China and the countries of origin. In this paper, the number of friendship cities established by bilateral local provinces and states is expressed, and the specific data comes from the "friendship city statistics" of China international federation of friendship cities.

\section{f. $\quad$ Controlled Variables}

By referring to the common practices in existing literatures, this paper uses the per capita GDP (GDPP) of the country of origin to reflect the local economic development level, and the geographical distance (DIS) of the capital of China and the country of origin to reflect the distance between the two countries. Per capita GDP $(G D P P)$ is used to reflect the economic consumption capacity of local residents, and population $(P O P)$ is used to reflect the scale of local students.

Distance is a multidimensional concept, which can refer to the spatial distance between two objects or the cognitive difference between individuals. In order to fully understand the influence of different regions and countries on spatial and cultural factors, this paper analyzes the constraints of distance on studying in China based on multi-dimensional distance. We mainly adopt the two main distance variables, geographical distance $(D I S)$ and cultural distance $(C D)$, to reflect the influence of the distance between the two countries on the geographical convenience and culture of international students in China. In Weber's (2010) theory of industrial location, the influence of spatial distance on the distribution of economic activities is particularly mentioned. Krugman (1991) et al. gradually formed the discipline of spatial economics. We believe that the geographic distance data comes from the CEPII database, and the cultural distance measurement comes from the founder Hofstede's model. There are four main dimensions of difference: power distance, collectivism/individualism, masculinity/feminism and uncertainty avoidance. The size of cultural differences is calculated by referring to the methods of Kogut and Singh (1988):

$$
C D_{i}=\sum_{k=1}^{4}\left[\left(I_{k i}-I_{k c}\right)^{2} / V_{k}\right] / 4
$$

In the formula above, $I_{k i}$ represents the value of the $i^{\text {th }}$ sample country in the $k^{\text {th }}$ cultural dimension. $I_{k c}$ represents the value of China (mainland) in the $k^{\text {th }}$ cultural dimension. $V_{k}$ represents the variance of the values of the $k^{\text {th }}$ cultural dimension in all sample countries. The data of the four dimensions are manually sorted from Hofstede's official website. In order to reduce the influence of heteroscedasticity, the natural logarithm of some variables was processed in this paper, as shown in Table 1.

Table 1 Variable Symbol

\begin{tabular}{|c|c|c|c|c|c|c|}
\hline Symbol & Variable & $\begin{array}{l}\text { Number } \\
\text { of Samples }\end{array}$ & Average Value & Standard Deviation & Minimum & Maximum \\
\hline Instu & $\begin{array}{c}\text { The natural logarithm } \\
\text { of the number of } \\
\text { foreign students in } \\
\text { China }\end{array}$ & 358 & 8.0361 & 1.1917 & 4.8828 & 11.1096 \\
\hline degree & $\begin{array}{c}\text { Bilateral diplomatic } \\
\text { degrec assignment }\end{array}$ & 432 & 2.4572 & 1.7182 & 1 & 5 \\
\hline dtime & $\begin{array}{l}\text { Time of establishing } \\
\text { diplomatic relations }\end{array}$ & 432 & 38.4722 & 14.2193 & 11 & 65 \\
\hline visit & $\begin{array}{c}\text { Overall bilateral } \\
\text { political diplomacy }\end{array}$ & 396 & 1.6944 & 1.8428 & 0 & 11 \\
\hline feity & Friendship city & 432 & 45.5278 & 66.0965 & 1 & 262 \\
\hline Indist & $\begin{array}{l}\text { Natural logarithm of } \\
\text { geographic distance }\end{array}$ & 432 & 8.5594 & 0.6613 & 6.8624 & 9.6116 \\
\hline culture & Cultural distance & 312 & 2.4054 & 1.1057 & 0.3721 & 3.8454 \\
\hline Ingdpp & $\begin{array}{l}\text { Natural logarithm of } \\
\text { GDP per capita }\end{array}$ & 422 & 8.3003 & 1.7678 & 5.1353 & 11.1221 \\
\hline Inpop & $\begin{array}{l}\text { The natural logarithm } \\
\text { of the population }\end{array}$ & 432 & 8.3903 & 1.2154 & 5.5090 & 11.7716 \\
\hline
\end{tabular}

\section{Basic Model}

This paper takes into account the population of the country, the per capita income of the country, and the cultural and geographical distance between the country and China. According to the research hypothesis, the model can be set as the following equations:

$$
\begin{aligned}
& \text { LnStuit }=\alpha+\beta_{1} \operatorname{deg} \text { ree }_{i t}+\theta_{i t}+\varepsilon_{i t} \\
& \text { LnStu }_{i t}=\alpha+\beta_{2} \text { Dtime }_{i t}+\theta_{t}+\varepsilon_{i t} \\
& \text { LnStu }_{i t}=a+\beta_{3} \text { Visitit }+\theta_{t}+\varepsilon_{i t} \\
& \text { LnStuit }=\alpha+\beta_{2} \text { Dtime }_{i t}+\theta_{t}+\varepsilon_{i t}
\end{aligned}
$$

In the equations above, $i$ represents country, $t$ represents year. student refers to the number of international students in China; degree is the degree of bilateral diplomacy between the two countries. dtime is the time when the two countries establish diplomatic relations; visit is an overall bilateral political and diplomatic behavior; fcity is the number of sister cities.

$\theta_{i t}$ number of international students in China, including: Geographical distance variable (dist), Cultural distance variable $(C D)$,

GDP per capita of the other country ( $g d p p)$ and The population of the other country (pop). And $\boldsymbol{E}_{i}$ is the random error term independent of the individual and time. 


\section{Extended Model}

In recent years, investigating the influence of cultural differences on international trade has gradually become an important research direction (Liu Wenyu, 2016). For the factors of economic development, economists have experienced a change from focusing on the accumulation of factors of production and technological progress to focusing on the institutional factors. Scholars have begun to explore deeper factors, including geographical, historical and cultural factors (Spolaore,2012). In this new field, the role of culture has received special attention. Some scholars believe that cultural complementarity will promote international trade, but more scholars believe that cultural differences between countries (regions) will increase the cost of bilateral trade, which is not conducive to trade.

We preliminarily predict that for countries along the Belt and Road, the greater the cultural distance from China, the greater the cultural difference between different groups, which is likely to lead to estrangement, prejudice and lack of trust between groups and hinder the economic exchanges between groups (Spolaore \& Waczing, 2009). Thus, international students will encounter greater obstacles in life, teaching and cultural adaptation. Therefore, we predict that the influence of cultural distance on the number of foreign students in China is negative. In order to further investigate the role of core variables, we will make an interactive term of four core variables and cultural distance respectively, and conduct classified regression to test the regulatory effect above, and analyze under what conditions core variables can better play a role in foreign students studying in China. The specific model is as follows:

$$
\begin{aligned}
& \text { LnStuit }_{i t} \alpha+\beta_{1} \operatorname{deg} \text { ree }_{i t}+\beta_{5} \operatorname{deg} \text { ree }_{i t} * \text { culture }_{i t}+\theta_{t}+\varepsilon_{i t} \\
& \text { LnStuit }=\alpha+\beta_{2} \text { Dtime }_{i t}+\beta_{6} \text { Dtimeit }^{*}{ }^{*} \text { culture }_{i t}+\theta_{t}+\varepsilon_{i t} \\
& \text { LnStuit }=\alpha+\beta_{3} \text { Visitit }+\beta_{7} \text { Visitit }^{*} \text { culture }_{i t}+\theta_{t}+\varepsilon_{i t} \\
& \text { LnStuit }=\alpha+\beta_{4} \text { Fcity }_{t}+\beta_{8} F_{\text {cityit }} * \text { cultureit }+\theta_{t}+\varepsilon_{i t}
\end{aligned}
$$

\section{EMPIRICAL RESULTS}

\section{A. The Relationship Between Control Variables and the} Number of Foreign Students in China

In the four basic models, the regression coefficients of geographical distance $(D I S)$ are $-1.2618,-1.3345,-1.2079$ and -1.0886 , which are all significant, indicating that the countries along the Belt and Road with the farther geographical distance are, the fewer students will study in China.

The regression coefficients of cultural distance are $0.1013,-0.0 .0588,-0.0 .0270$ and -0.1063 respectively, which are significantly negative correlation, indicating that the farther the cultural distance between countries along the Belt and Road and China is, the fewer students will come to study in China.

What's more, there is a significant positive correlation between the regression coefficient of the population of the country of origin and the number of students studying in China.

And the regression coefficient of per capita income $(G D D)$ is significantly positively correlated, indicating that countries with higher economic development level along the Belt and Road will have more students studying in China.

\section{B. The Relationship Between Core Variables and the Number of Foreign Students in China}

In order to investigate the relationship between core variables and foreign students in China, we conducte an empirical test according to the basic model, and the results are shown in Table 2.

$\mathrm{R}^{2}$ is greater than $68 \%$. It can be seen from table 3 that bilateral diplomatic positioning has a significant positive effect, that is, the higher the degree of bilateral diplomatic positioning is, the more students come to China, and the coefficient is at the significance level of $1 \%$.

The regression coefficient of the time of establishment of diplomatic relations between the two sides is 0.054 , and at the significant level of $1 \%$, indicating that the time of establishment of diplomatic relations has a significant positive effect on foreign students in China, that is, the longer the time of establishment of diplomatic relations between the two countries, the more the number of foreign students in China will increase.

The regression coefficient of bilateral high-level visits is 0.0677 , which is above the significant level of $5 \%$. This suggests that short-term diplomacy, such as bilateral highlevel meetings, contributes to the number of foreign students coming to China.

The regression coefficient of friendship cities is 0.0044 , which is at the significant level of $1 \%$. Therefore, as an informal institutional arrangement of bilateral political relations, friendship cities are conducive to the number of foreign students in China. Based on the construction of the silk road economic belt, friendship cities provide an effective channel for expanding cooperation and exchanges.

\begin{tabular}{|c|c|c|c|c|}
\hline & Model 1 & Model 2 & Model 3 & Model 4 \\
\hline Constant term & $\begin{array}{l}14.3126 \\
(36.5175)^{\cdots}\end{array}$ & $\begin{array}{l}12.2360 \\
(18.0850) \cdots\end{array}$ & $\begin{array}{l}11.6417 \\
(57.5789)^{\prime} \cdots\end{array}$ & $\begin{array}{l}12.2758 \\
(70.6119)^{\cdots}\end{array}$ \\
\hline Indist & $\begin{array}{l}-1.2618 \\
(-40.4487) \ldots\end{array}$ & $\begin{array}{l}-1.3345 \\
(-16.7534)^{\cdots}\end{array}$ & $\begin{array}{l}-1.2079 \\
(-27.2897) \cdots\end{array}$ & $\begin{array}{l}-1.0886 \\
(-27.2029)^{\cdots}\end{array}$ \\
\hline culture & $\begin{array}{l}-0.1013 \\
(-3.2779) \cdots\end{array}$ & $\begin{array}{l}-0.0588 \\
(-2.9947) \ldots\end{array}$ & $\begin{array}{l}-0.0270 \\
(-1.7804)^{*}\end{array}$ & $\begin{array}{l}-0.1063 \\
(-8.7107) \cdots\end{array}$ \\
\hline Ingdpp & $\begin{array}{l}0.2619 \\
(19.0923)^{\cdots}\end{array}$ & $\begin{array}{l}0.4995 \\
(18.0451) \cdots\end{array}$ & \begin{tabular}{|l}
0.3610 \\
$(18.8891)^{\cdots}$
\end{tabular} & $\begin{array}{l}0.2416 \\
(8.6137) \ldots\end{array}$ \\
\hline degree & $\begin{array}{l}0.2628 \\
(7.5648)^{\cdots} \\
0.1415 \\
(9.8107) \cdots\end{array}$ & $\begin{array}{l}0.0681 \\
(1.7841)^{\circ}\end{array}$ & \begin{tabular}{|l}
0.4149 \\
$(16.8104) \cdots$
\end{tabular} & $\begin{array}{l}0.3523 \\
(24.3462) \cdots\end{array}$ \\
\hline $\begin{array}{l}\text { dtime } \\
\text { visit }\end{array}$ & & $\begin{array}{l}0.0540 \\
(12.9172) \cdots\end{array}$ & $\begin{array}{l}0.0677 \\
(1.9931) *\end{array}$ & \\
\hline fcity & & & & $\begin{array}{l}0.0044 \\
(7.2382) \ldots\end{array}$ \\
\hline F-test value & $\begin{array}{l}999.3591 \\
(0.0000)^{\cdots}\end{array}$ & $\begin{array}{l}303.4077 \\
(0.0000)^{\cdots}\end{array}$ & \begin{tabular}{|l}
94.8185 \\
$(0.0000) \cdots$
\end{tabular} & $\begin{array}{l}341.8075 \\
(0.0000) \cdots\end{array}$ \\
\hline $\mathrm{R}^{2}$ & 0.9480 & 0.8470 & \begin{tabular}{|l}
0.6337 \\
\end{tabular} & 0.8618 \\
\hline Adjusted R2 & 0.9470 & 0.8442 & $\mid 0.6270$ & 0.8593 \\
\hline $\begin{array}{c}\text { Number of } \\
\text { samples }\end{array}$ & 280 & 280 & 280 & 280 \\
\hline
\end{tabular}

All of the above are in line with theoretical and practical expectations.

Table 2 Estimation Results of the Basic Model

Note: the variables in brackets are $t$ statistics; In each test bracket is the adjoint probability of the statistic; $* * *, * *$ and * mean significant at the $1 \%, 5 \%$ and $10 \%$ levels respectively. 


\section{The Interaction between Politics and Culture}

As shown in the basic model, the coefficient of cultural distance on the number of foreign students in China is significantly negative. After the interaction between core variables and cultural distance variables, the results are shown in Table 3.

The first and second columns are the interactive variables of diplomatic degree, time of establishment of diplomatic relations and cultural distance between the two sides. According to the regression results, the diplomatic degree and the time of establishing diplomatic relations between the two sides have significantly adjusted the influence of cultural distance on the number of foreign students in China. With the establishment of diplomatic relations between the two sides, the deepening of bilateral diplomacy will enable people from all over the world to better understand China, provide more opportunities for China to attract foreign students and increase the desire of foreign students to study in China. According to the regression results, the diplomatic degree and the time of establishing diplomatic relations between the two sides have significantly adjusted the influence of cultural distance on the number of foreign students in China. With the increase of the time of the establishment of diplomatic relations between the two sides and the deepening of bilateral diplomacy, people from all over the world can enhance their understanding of China, provide more opportunities for China to attract foreign students, increase the desire of foreign students to study in China, and effectively change the negative impact of cultural distance.

The third column adds the interaction item of bilateral high-level visits and cultural distance. The regression coefficient is 0.0268 , which is at the significant level of $5 \%$. It can be seen from the regression coefficient that bilateral high-level visits, a political and diplomatic activity, contribute to deepening the strategic and economic dialogue mechanism between the two countries. The exchange of visits between leaders of the two countries will enhance communication and political mutual trust between the two countries. It will not only provide the other side with opportunities to understand China, but also help establish a good image of China and attract more students to study in China.

The fourth column shows the interaction term between sister cities and cultural distance, and the regression coefficient is 0.0014 , which is at the significant level of $1 \%$. It can be seen that the establishment of sister cities helps to eliminate the negative impact of cultural distance, which indicates that with China's active participation in global governance, China's cooperation with overseas local governments is also increasingly extensive. As can be seen from the BBS of the Chinese and French governments and greater Mekong sub-region international cooperation mechanisms, the international cooperation of local governments has also gone deep into almost all local affairs, providing a good condition for the expansion and acceptance of the common development of both sides.
Table 3 The Estimated Results of the Interaction Model

\begin{tabular}{|c|c|c|c|c|}
\hline & Model 5 & Model 6 & Model 7 & Model 8 \\
\hline Constant term & \begin{tabular}{|l|}
14.3235 \\
$(38.0023)^{\prime} \cdots$
\end{tabular} & $\begin{array}{l}9.7085 \\
(19.7128)^{\cdots}\end{array}$ & $\begin{array}{l}11.9479 \\
(41.5277)^{\cdots}\end{array}$ & $\begin{array}{l}13.2220 \\
(53.2553)^{\cdots}\end{array}$ \\
\hline Indist & $\begin{array}{l}-1.3335 \\
(-42.2349) \cdots\end{array}$ & $\begin{array}{l}-0.8362 \\
(-21.1401)^{\cdots}\end{array}$ & $\begin{array}{l}-1.2329 \\
(-33.4703)^{\ldots}\end{array}$ & $\begin{array}{l}-1.2154 \\
(-34.2290) \ldots\end{array}$ \\
\hline culture & $\begin{array}{l}-0.1574 \\
(-4.5223)^{\cdots}\end{array}$ & $\begin{array}{l}-0.9509 \\
(-14.7917)^{\cdots}\end{array}$ & $\begin{array}{l}-0.0676 \\
(-2.1441)^{*}\end{array}$ & $\begin{array}{l}-0.1174 \\
(-7.4512)^{\cdots}\end{array}$ \\
\hline Ingdpp & $\begin{array}{l}0.2854 \\
(20.4743)^{\cdots}\end{array}$ & $\begin{array}{l}0.3819 \\
(27.2449) \cdots\end{array}$ & $\begin{array}{l}0.3606 \\
(18.8392)^{\prime}\end{array}$ & $\begin{array}{l}0.2485 \\
(12.6600) \cdots\end{array}$ \\
\hline degree* ${ }^{*}$ culture & \begin{tabular}{|l}
0.3414 \\
$(8.8268) \cdots$ \\
0.0397 \\
$(5.9243) \ldots$
\end{tabular} & $\begin{array}{l}0.3441 \\
(9.8402) \cdots\end{array}$ & $\begin{array}{l}0.4151 \\
(18.2783)^{\cdots} \cdots\end{array}$ & $\begin{array}{l}0.3701 \\
(41.3238) \cdots\end{array}$ \\
\hline $\begin{array}{l}\text { dtime* culture } \\
\text { visit*culture }\end{array}$ & & $\begin{array}{l}0.0163 \\
(15.0160)^{\cdots} \cdots\end{array}$ & $\begin{array}{l}0.0268 \\
(2.2605) *\end{array}$ & \\
\hline fcity*culture & & & & $\begin{array}{l}0.0014 \\
(8.1890) \ldots\end{array}$ \\
\hline F-test value & $\begin{array}{l}1094.592 \\
(0.0000) \cdots\end{array}$ & $\begin{array}{l}649.3985 \\
(0.0000)^{\cdots}\end{array}$ & $\begin{array}{l}96.3036 \\
(0.0000) \cdots\end{array}$ & $\begin{array}{l}247.7942 \\
(0.0000) \cdots\end{array}$ \\
\hline $\mathrm{R}^{2}$ & 0.9523 & 0.9221 & 0.6373 & 0.8188 \\
\hline Adjusted $\mathrm{R}^{2}$ & 0.9514 & 0.9207 & 0.6307 & 0.8155 \\
\hline Number of samples & 280 & 280 & 280 & 280 \\
\hline
\end{tabular}

Note: the variables in brackets are $t$ statistics; In each test bracket is the adjoint probability of the statistic; ***, ** and * mean significant at the $1 \%, 5 \%$ and $10 \%$ levels respectively.

\section{CONCLUSIONS AND POLICY RECOMMENDATIONS}

\section{A. Conclusions}

By empirical model, this paper draws the overall bilateral political diplomacy for the number of foreign students of countries along the Belt and Road has obvious positive effect, namely, higher degree of political and diplomatic, longer time of the establishment of diplomatic relations, more frequent bilateral high-level meeting and more construction of friendship city bring more number of foreign students in the country of origin to study in China. However, the Belt and Road concept faces difficulties and challenges in reality. Countries with "different ethnic groups", "different faiths" and "different cultural backgrounds" cannot share the long-cherished aspiration of peace and common development without gradually removing barriers to exchanges. Therefore, we further find that political and diplomatic factors can effectively reduce the negative effects of cultural distance and play the role of politics in serving the economy and society.

\section{B. Policy Recommendations}

Firstly, on the basis of sound bilateral diplomacy, we should make full use of diplomatic means to promote China's participation in global education governance and increase the scale and level of education for overseas students in China. We will use platforms such as bilateral and multilateral diplomacy to proactively carry out effective foreign diplomatic publicity, make achievements in education development an important part of foreign publicity and promotion, and strengthen China's image of responsibility in international education governance. On the basis of enhancing the comprehensive strength of China's education, we should strengthen exchanges and exchanges in the field of higher education, give better play to the voice and influence of China's higher education in the world, and 
participate in international cooperation and exchanges in a more active manner. In addition, we should take an active part in the formulation of international education rules and deepen cooperation in bilateral education, especially in higher education and vocational education. We should give full play to the role of UNESCO as an important platform for cooperation in education, establish a regular high-level consultation mechanism, consolidate and upgrade international cooperation in education, and identify favorable opportunities to put forward new proposals, initiatives and programs of our own.

Secondly, through bilateral diplomatic channels at the government level, the education action of co-building the Belt and Road will be promoted. Cooperation should be the education as the Belt and Road initiative of one of the important areas and key issues, and actively advocate the Belt and Road countries to participate in building the education community, to carry out multi-level and diverse education interconnectivity, talents training, scientific research platform and project cooperation, the silk road construction of cooperation mechanism and so on. In addition, it is necessary to meet the educational needs of countries along the belt and road, learn from educational experience, get through the mutual recognition of academic qualifications and credit exchange between China and countries along the Belt and Road, promote various forms of exchanges and exchanges between teachers and students, and establish a closer educational cooperation and exchange mechanism. We should support institutions of higher learning and vocational education with good basic conditions, distinctive features and prominent advantages to actively go global, establish schools in countries and regions along the belt and road, expand research and development institutions and increase their influence. We should strengthen practical cooperation in education with countries along the belt and road and other developing countries, and promote the opening up of education to the outside world with clear priorities, distinctive features, prominent priorities and win-win cooperation. Also, we should strengthen the top-level design of the development plan for educational exchanges with other countries, and strengthen cooperation with southeast Asian countries in a planned, multi-tiered and step-by-step manner.

Thirdly, to actively encourage and strongly support the development of people-to-people diplomacy and make it a bridge for educational exchanges and cooperation. We should give full play to the role of people-to-people diplomacy, promote people-to-people and cultural exchanges between China and foreign countries, and expand channels for international educational cooperation and exchanges. To give full play to the exchanges and cooperation among people and organizations in the fields of education, science, education and culture, and give full play to the positive role of cultural and artistic exchanges in promoting public awareness. What's more, We should establish extensive people-to-people diplomatic relations, pool the strength of all sectors of society, and make good use of sister cities to tell China's stories, showcase China's achievements in development, spread China's ideas, and increase China's influence and appeal to countries of origin.

\section{REFERENCES}

[1] Zheng X. R., On the Advantages of China's Development of International Students' Education in China- Also on the Significance of Developing International Students' Education in China, The Modern Education Journal, 2005(2):26-29.

[2] Xu C. S. \& Wang Y. H., Research on the Influence of Confucius Institutes on China's Foreign Direct Investment, International Business, 2016(2):58-68.

[3] Song H. S. \& Liu L., Why do Foreign Students Come to Study in China, Journal of Higher Education, 2004(11):31-38.

[4] Lin H., Xie Z. Z. \& Zheng R. Y., Does the Confucius Institute Promote Overseas Students to Study in China- Based on the Empirical Test of Panel Data from 40 Countries in 2004-2014, International Business, 2016(5):52-65.

[5] Zhao Z. X., Towards the Country of Asia's Largest Destination for Studying Abroad- A Summary of New China's Study in China, China Scholars Abroad, 2015(7):4-7.

[6] Yang L. X., Liu X. G. \& Zhang J., How do Bilateral Political Relations Affect Foreign Direct Investment: Based on the Perspective of Binary Margin and Investment Success or Failure, China Industrial Economics, 2016(11):56-72.

[7] Cao L., Yuan D. S. \& Xu X. C., The Establishment of Diplomatic Relations and the Binary Margin of Agricultural Products Export: From the Perspective of Export Destinations, Macroeconomics, 2016(4): 106-114

[8] Nitschka T., The Risk Premium on the Euro Area Market Portfolio: The Role of Real Estate, Ssrn Electronic Journal, 2008.

[9] Vilcek J., Klion A., Henriksendestefano D., et al. Defective Gammainterferon Production in Peripheral Blood Leukocytes of Patients with Acute Tuberculosis, Journal of Clinical Immunology, 1986, $6(2): 146-51$.

[10] Svensson E I, Eroukhmanoff F, Karlsson K, et al. A Role for Learning in Population Divergence of Mate Preferences, Evolution, 2010, 64(11):3101-3113.

[11] Chen W. L. \& Wu X. M., Changes in Import Demand of Countries along the Maritime Silk Road and China's Countermeasures, International Economics And Trade Research, 2015, 1(4):87-100.

[12] He S. F. \& Guo Y. D., Location Analysis of China's Foreign Direct Investment: Is the Political Factor Important?, Shanghai Journal of Economics, 2009(3):3-10.

[13] Guo Y. \& Xu C. S., Bilateral High-level Meetings and Direct Investment by China in Countries along the "Belt and Road", Journal of International Trade, 2016(2):26-36.

[14] Krugman P., Increasing Returns and Economic Geography, Journal of Political Economy, 1991, 99(Volume 99, Number 3):483-499.

[15] Kogut B, \& Singh H., The Effect of National Culture on the Choice of Entry Mode, Journal of International Business Studies, 1988, 19(3):411-432.

[16] Spolaore E., What Is European Integration Really About? A Political Guide for Economists, Journal of Economic Perspectives, 2013, 27(3):125-144.

[17] Spolaore E, \& Wacziarg R., How Deep Are the Roots of Economic Development?, Journal of Economic Literature, 2012, 51(2):325369.

[18] Li W. Y. \& Liu H. D., The Construction of the "Belt and Road" from the Perspective of Multidimensional Distance: Space, Economy, Culture and System, International Economics And Trade Research, 2016, 32(6):99-112.

[19] Lian D. X., Economics Effects of Confucius Institute, Nanjing: Nanjing University Press, 2014.

[20] Alfred Weber, Theory of the Location of Industries, Beijing: The Commercial Press, 1997. 